\title{
ESTUDO DA OTIMIZAÇÃO E REDUÇÃO DA CONTA FRETE DA EMPRESA MOINHO PAULISTA S/A - NITA ALIMENTOS
}

\section{STUDY ON OPTIMIZATION AND ACCOUNT REDUCTION COMPANY FREIGHT MILL PAULISTA S / A - NITA FOOD}

\section{Elizãngela de Jesus Oliveira ${ }^{1}$, Darly Fernando Andrade ${ }^{2}$, Larissa Farias Almeida ${ }^{3}$ \\ ${ }^{1}$ Universidade Federal do Amazonas/UFAM. ${ }^{2}$ Universidade Federal De Uberlândia/UFU. ${ }^{3}$ Universidade Federal do Amazonas/UFAM. ${ }^{1 *}$ elizoliveirajesus@gmail.com ${ }^{2}$ darly@ufu.br ${ }^{3}$ almlarissa@gmail.com}

\section{ARTIGO INFO.}

Recebido em: 22.04.2020

Aprovado em: 04.11.2020

Disponibilizado em: 05.11.2020

\section{Palavras-chave:}

Cargas; Otimização; Custos; Lucratividade.

\section{KEYWORDS:}

Loads; Optimization; Costs; Profitability.

\section{*Autor Correspondente: Oliveira, E. de J.}

\section{RESUMO}

O presente estudo aborda a temática da otimização de carga em busca da redução dos custos do frete, tendo em vista um projeto que pretende facilitar o trabalho de transporte dos produtos. $\mathrm{O}$ estudo se justifica pela relevância do tema na atualidade, quando as empresas buscam seu espaço no mercado competitivo e querem a potencialização de seus resultados. $\mathrm{O}$ objetivo geral da pesquisa é analisar o processo de otimização de carga como recurso para reduzir os valores do frete no ambiente alvo desta pesquisa, que tem como objetivos específicos: discutir a logística e o seu papel na atualidade das organizações; abordar a importância das tecnologias na otimização de resultados empresariais; ressaltar o volume das cargas como fator determinante para redução do custo do frete, gerando maior lucratividade. A metodologia utilizada foi, inicialmente, pautada na pesquisa bibliográfica, posteriormente, no estudo de caso da empresa. Para que assim, se atingisse os resultados da pesquisa. Em acréscimo, é abordado neste estudo, os resultados da proposta de utilização de um roteirizador na otimização dos fretes e redução de custo desse processo.

\begin{abstract}
This study addresses the topic of cargo optimization in order to reduce freight costs, in view of a project that aims to facilitate the work of transporting products. The study is justified by the relevance of the theme today, when companies seek their space in the competitive market and want to maximize their results. The general objective of the research is to analyze the process of load optimization as a resource to reduce freight values in the target environment of this research, which has as its specific objectives: to discuss logistics and its role in organizations today; address the importance of technologies in optimizing business results; highlight the volume of cargo as a determining factor for reducing the cost of freight, generating greater profitability. The methodology used was initially based on bibliographic research, later on the case study of the company. In order to achieve the search results. In addition, in this study, the results of the proposal to use a scriptwriter to optimize freight and reduce the cost of this process are discussed.
\end{abstract}




\section{INTRODUÇÃO}

A elevada competitividade no mercado leva as organizações a buscar formas de potencializar seus resultados, trazendo maior lucratividade e desempenho. O transporte é uma questão fundamental para elevar o nível das atividades econômicas. Para a confirmação dessa ideia, é preciso comparar a economia em países desenvolvidos e em desenvolvimento, que normalmente têm áreas de consumo e produção próximas, sem que seja preciso buscar produtos de locais mais distantes (Branco, \& Gigioli, 2014).

Através do êxodo rural, nos países em desenvolvimento, as pessoas voltaram sua concentração para os centros urbanos, e caso haja um sistema de transporte satisfatório, mesmo os produtos de mercados distantes terão custos acessíveis (Ballou, 1993; Branco, \& Gigioli, 2014).

A redução de custos é fundamental, assim como a melhoria do nível do serviço que é desempenhado e oferecido aos clientes. Por isso, as empresas passaram a investir e direcionar os seus esforços para otimizar suas atividades logísticas (Matos Junior, et al., 2013). Nesse contexto, o presente estudo aborda a temática da otimização da carga na busca da redução dos custos do frete. Considerando um projeto que pretende facilitar o trabalho de transporte dos produtos.

O estudo se justifica pela relevância do tema na atualidade, quando as empresas buscam seu espaço no mercado competitivo e querem a potencialização de seus resultados.

O objetivo geral da pesquisa é analisar o processo de otimização da carga como recurso para reduzir os valores do frete em determinada empresa pesquisada. Tal objetivo é desdobrado nos seguintes objetivos específicos quais sejam: discutir a logística e o seu papel na atualidade das organizações; abordar a importância das tecnologias na otimização de resultados empresariais; ressaltar o volume das cargas como fator determinante para redução do custo do frete, gerando maior lucratividade.

Em um primeiro momento foi realizada uma pesquisa bibliográfica para embasar o estudo teoricamente e posteriormente realizado um estudo de campo com observações diretas no processo utilizado da empresa estudada.

\section{A Importância da Logística}

A logística é uma área do conhecimento que aborda a movimentação e o armazenamento de materiais para que os mesmos estejam no local e momento certos, atendendo à demanda dos clientes, diminuindo custos desnecessários e ampliando a qualidade e o fluxo de informações (Matos Junior, et al., 2013).

Segundo Pinto et al. (2013), num contexto atual, de elevada competitividade empresarial, as organizações buscam um aperfeiçoamento dos seus processos, através da redução de custos para o atendimento das expectativas dos consumidores, a logística trabalha na otimização dos processos que englobam a fabricação de um produto, desde a compra de sua matéria- prima, até a sua entrega. 
Morales, et al., (1997) destacam que a logística, há tempos, tem sido alvo dos empresários para estudos de seus conceitos e ampliação de suas tecnologias. Sendo importante destacar que a logística não aborda somente a distribuição física dos produtos finais, mas sim todas as atividades que estão relacionadas a essa entrega final, como o transporte, manutenção de estoque, processamento de pedidos, armazenamento, movimentação e outras atividades. Sendo que a logística tem o objetivo principal de contribuir para um custo reduzido e a disponibilidade dos produtos desejados pelos seus clientes.

Pinto, et al., (2013) explica que o transporte está entre as principais atividades de distribuição física, fundamental na atualidade, uma vez que o perfil de compra dos clientes, pretende-se uma redução das barreiras geográficas, porque se tem urgência na aquisição dos produtos. Os clientes procuram por produtos que estão disponíveis, independente de seu lugar de fabricação. Normalmente, a logística envolve os esforços do fluxo de distribuição física, aproximando o produto do cliente. Geralmente, a informação faz parte de todas as partes do processo, não sendo possível pensar no desenvolvimento sem as tecnologias disponíveis no contexto de transporte.

O transporte é o processo logístico que apresenta maior custo, por isso a escolha do modal que ofereça qualidade com menor custo é essencial para que o produto chegue ao consumidor com preço competitivo. No Brasil as empresas não têm muitas opções de escolha devido à falta de infraestrutura e falta de interligação entre os modais existentes, o que as fazem, em sua maioria, optar pelas rodovias, assim encarecendo seus produtos devido aos seus altos custos de manutenção (Pinto, et al., 2013, p. 13).

De acordo com Imam (2011), o transporte rodoviário de cargas tem a responsabilidade de mobilizar aproximadamente $80 \%$ do total das cargas transportadas; considerando que as estatísticas apontam para o transporte dutoviário (transferência de fluidos) e transporte de cabotagem, que envolve o transporte de areia, somente para destacar as estatísticas mais populares. Ainda que os caminhões sejam fundamentais para a economia, trata-se de um negócio complexo. Por não haver barreiras, esse mercado atrai pequenas e novas empresas, que acabam por reduzir os valores transmitidos aos clientes, para se manterem no mercado. Muitos são os caminhoneiros que trabalham pelo preço do frete, eliminando esse serviço da empresa, que oferecem custos menores, dificultando ainda mais o trabalho de transporte para as empresas.

De acordo com a Revista Logística do Imam (2017), a tecnologia de informação tem sido um recurso muito usado no transporte rodoviário das cargas, consolidando softwares e conceitos do TMS - Transportation Management System, que é formado por três módulos: o planejamento, acompanhamento e controle. Para a garantia de sua eficiência é preciso de uma interface com o software corporativo empresarial, favorecendo as informações, tanto interna quanto externa, com recursos disponibilizados na internet.

Planejamento: é caracterizado pelo módulo roteirizador, que utiliza mapas digitalizados, que permitem a identificação de restrições e alternativas de trajetos. Tem por objetivo a otimização de recursos como a ocupação (da capacidade) e aproveitamento (do tempo) dos veículos, redução da distância total percorrida e melhor precisão nos prazos de entrega. $\mathrm{O}$ 
resultado é a redução de custos e um melhor nível de serviço a clientes, além de servir como referência para verificação de desvio pelo rastreador (gerenciamento de riscos) (Revista Logística do IMAM, 2017, p. 02).

O transporte é uma das ramificações mais importantes da logística, para que haja competitividade nesse cenário, é fundamental que seja realizado um planejamento adequado, considerando a infraestrutura com apoio especializado. Assim, é preciso que haja um bom funcionamento do sistema de transporte, com três fatores fundamentais: base de dados confiável para análise, tecnologia de informação e desenvolvimento de controles (Pinto et al., 2013).

\section{Projeto de Otimização de Carga para a Redução da Conta Frete}

Por conta da alta competitividade no cenário mercadológico atual, em muitos ramos, a marca deixou de ser o foco principal dos clientes, considerando que existem grandes semelhanças entre os produtos de uma mesma área. Por isso, entre as prioridades do cliente estão a qualidade do serviço/produto e o custo. Para que se atenda essas necessidades, as empresas precisam se adequar a métodos mais eficazes para solucionar problemas, satisfazendo clientes e conquistando sua fidelidade (Branco, \& Gigioli, 2014).

Na aplicação de um software numa empresa, é preciso considerar o indicador, que é a forma através da qual se mensura o desempenho das atividades, buscando o alcance das metas estabelecidas. Pautado em indicadores, se torna possível acompanhar o desempenho dos processos logísticos em relação à execução, custos e níveis de serviços, favorecendo a tomada de ações para resultados abaixo das metas e identificando gargalos para que se possa tomar ações preventivas e corretivas (Matos Júnior, et al., 2014).

Foi proposto um projeto para otimização da carga, através da roteirização de pedidos, através das seguintes fases: planejamento do projeto; conceituação e discussão da política de entrega; criação de um programa específico de roteirização; definição das regras para criação de rota; método do vizinho mais próximo. O projeto de roteirização despertou a ideia para implantação do programa da Totvs, que facilita a montagem de cargas de acordo com as regiões, pautado no desenvolvimento de um cadastro de veículos, em que constam a placa veicular e a capacidade do veículo, buscando a adequação e o carregamento do máximo de pedidos por veículo em uma região. A roteirização pode ser entendida como o processo de criação de roteiros ou itinerários, no qual os pontos de paradas geograficamente dispersos devem ser atendidos de acordo com suas necessidades, ao menor custo possível.

De acordo com Cunha (2000), a roteirização é usada para delimitar o processo de determinação de um ou mais roteiros, ou a sequência com que haverá paradas. Sendo que o objetivo da roteirização é visitar um grupo de pontos com distâncias variadas, que precisam ser atendidos.

Bertaglia (2003) destaca que as empresas que reconhecem a importância de melhorar são as que atingem mais sucesso. Por esse motivo, a implantação do roteirizador de pedidos se faz fundamental, quando há muitos pedidos a cumprir.

\section{@ $\odot \Theta \odot$}


Lima e Schebeleski (2013) explicam que a roteirização envolve muitos obstáculos, como: distância de um fornecedor para o outro; tempo para a entrega de alguma matéria-prima ou produto. Ainda citam Ballou (2001), que explica que a roteirização é uma atividade que tem o objetivo de encontrar os melhores trajetos para um veículo, com a apresentação de uma malha viária na qual se localizam os clientes. Essa pesquisa de trajetos tem o propósito de reduzir o tempo e a distância, contribuindo para a logística da empresa.

Assim, para se atingir a eficiência logística, é preciso que sejam definidos programas e roteiros. Bertaglia (2003) defende que os programas de computadores podem contribuir para que os roteiros sejam determinados, principalmente nos casos de múltiplas entregas ou recolhimento de matéria-prima ou produtos.

Segundo Bodin (1990), a problemática da roteirização de veículos pode ser compreendida partindo da importância do atendimento de conjuntos de clientes em vários pontos geográficos, partindo de um ponto central, que é o depósito dos produtos.

Segundo Valente (2008), as questões básicas do problema de roteirização são:

[...] (1) uma região geográfica é dividida em zonas; (2) a cada zona é alocado um veículo; (3) a cada veículo é designado um roteiro; (4) o serviço deverá ser realizado dentro de um tempo de ciclo predeterminado; (5) os veículos são despachados a partir de um depósito central, ou centro de distribuição (Valente, 2008, p. 182-183).

Os objetivos da criação do projeto foram: Combater solicitações de adicionais de frete onde as distâncias estão geograficamente dispersas; Alcançar um alto nível de serviço para o cliente; Automatizar $100 \%$ a montagem de cargas; Reduzir em $15 \%$ as não conformidades em transporte.

Segundo Branco e Gigioli (2014), o avanço em Sistemas de Informação têm exercido influências positivas na logística, buscando um desempenho cada vez melhor. Os softwares de roteirização são sistemas de informação mais usados pela cadeia logística, que são chamados de Sistema de Informação Geográfico (SIG) ou softwares de geoprocessamento.

Esses softwares são formados por sistemas de roteirização e programação de veículos, que buscam otimizar a rota, através de métodos matemáticos, que abrangem as variáveis interessantes de cada organização, dependendo do ramo de atividade e do que se pretende priorizar.

Conforme Novaes (2007) apud Matos Júnior et al. (2013), as formas de roteirização, normalmente são desenvolvidas recebendo o nome dos seus criadores. Nos sistemas de roteirização mais usados estão o método Clarke \& Writht e o método de varredura. Através desses métodos se pode construir um planejamento de rotas de forma eficiente, para executar as entregas da melhor maneira possível.

Para Ballou (1993), a construção de boas soluções para roteirizar e programar veículos tem se tornado mais difícil ao passo que as novas restrições são impostas. As janelas de tempo, os caminhões múltiplos com variadas capacidades de peso e cubagem, o tempo máximo para permanecer no volante em seus roteiros, as velocidades em diferentes áreas, barreiras de tráfego e intervalos para motoristas; todas essas questões prejudicam a agilidade do roteiro. 
Ravagnolli (2006) apud Branco e Gigioli (2014) defende que quando a empresa opta por adquirir um sistema roteirizador deve considerar alguns pontos relevantes para a tomada de decisões sobre qual mais se adéqua às suas necessidades. A aquisição de um roteirizador possibilita muitos ganhos para a organização, do ponto de vista financeiro, reduzindo custos operacionais e também eleva o nível do serviço, oferece ao cliente mais qualidade e satisfação.

Branco (2014) cita Martin (2010), que defende que ainda que os clientes novos sejam o que cada empresa busca constantemente, é importante destacar que os clientes já existentes podem trazer elevação nos lucros e tendem a comprar com mais frequência, e até mesmo realizar compras mais significativas. Além disso, o cliente que está fidelizado pela empresa, tende a atrair novos clientes.

Através de entregas rápidas e eficazes, que atendem às necessidades dos clientes já existentes, se torna possível que esses se mantenham satisfeitos e acreditem na constante atualização da empresa, elevando a credibilidade da organização diante de seus clientes.

Existem vários softwares que são disponibilizados ao público, sendo que cada um deles apresenta funcionalidades e complexidades próprias. Devido a isso, sem uma avaliação correta do roteirizador que se pretende adquirir, poderão ocorrer erros na entrada de dados, processamento de informações, entre outros problemas. Sistemas mal implantados e mal gerenciados resultam em uma fonte de prejuízo e problemas (Branco, \& Gigioli, 2014, p. 65).

O roteirizador apresentado nesse projeto foi o Rotped - Roteirizador de pedidos.

\subsection{Detalhes do projeto de roteirizador}

A seguir, são apresentados imagens e comentários que contribuem para a ilustração do roteirizador proposto, destacando suas vantagens e considerações importantes para justificar a utilização do mesmo.

Figura 1. Roteirização de pedidos

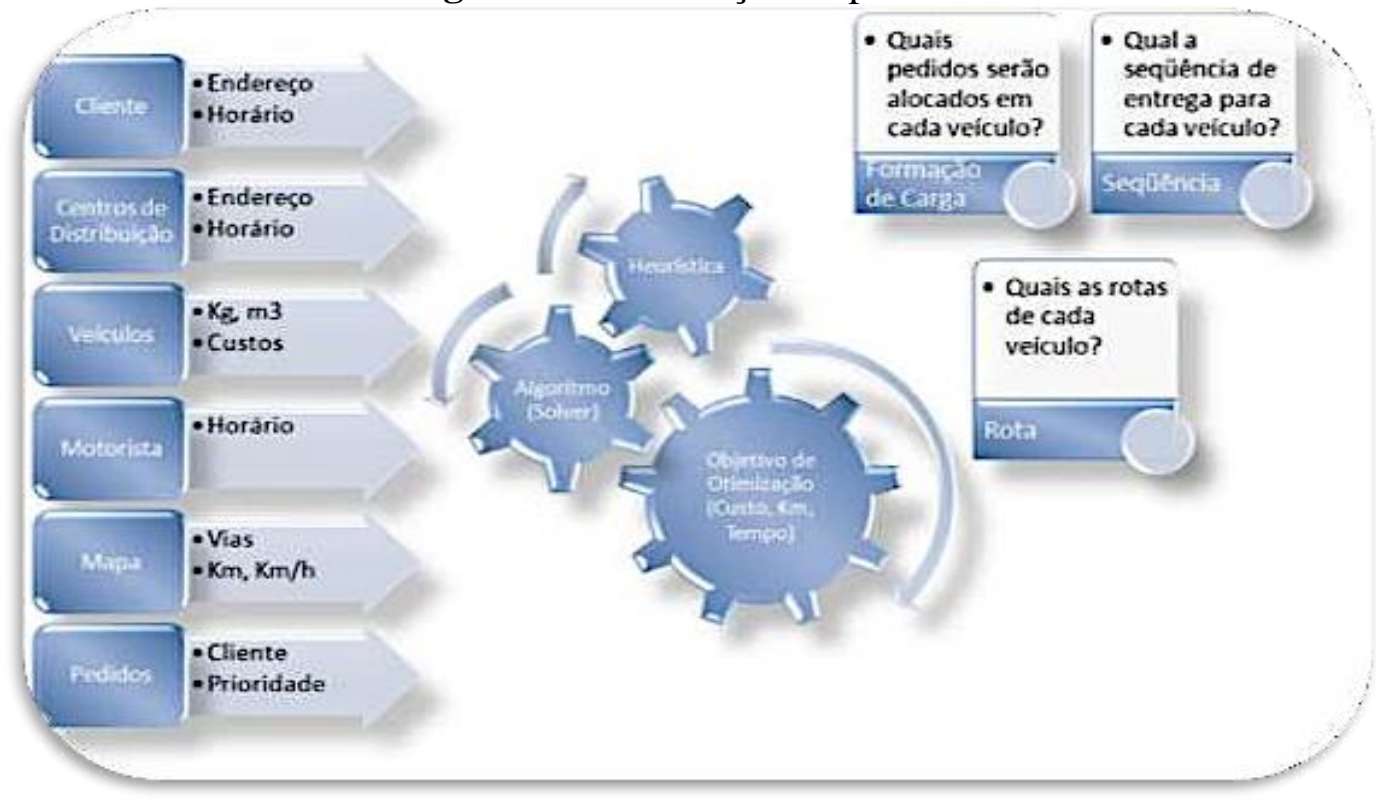

Fonte: Autores

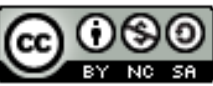


Na Figura 1 são apresentadas as questões abordadas no roteirizador de pedidos, com todos os detalhes relevantes nesse software, que podem contribuir para os resultados da organização.

Figura 2. Princípios da boa roteirização

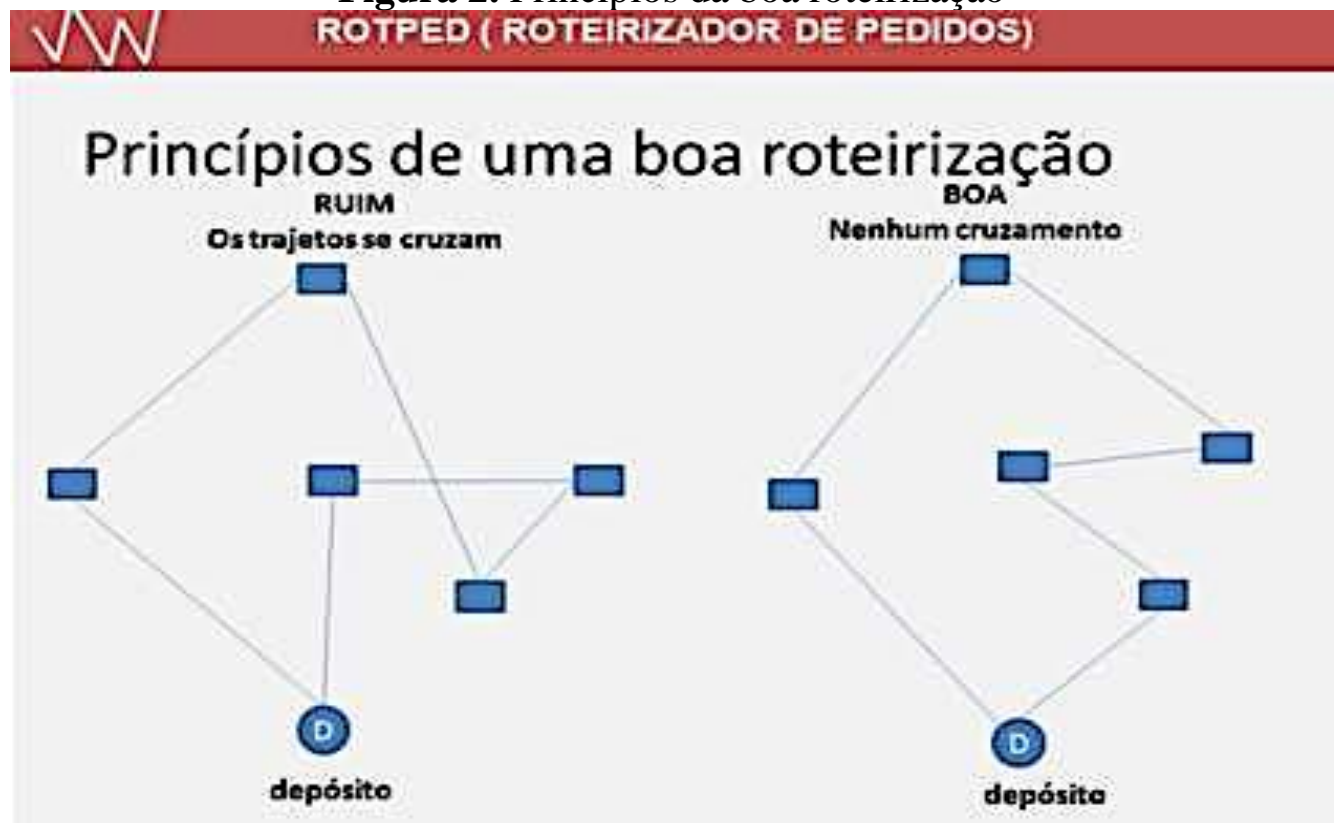

Fonte: Autores

Na Figura 2, ilustra-se a importância das rotas não se cruzarem, favorecendo uma entrega mais eficiente, que contribua para a qualidade do trabalho realizado e a quantidade de clientes atendidos.

Figura 3. Análise SWOT

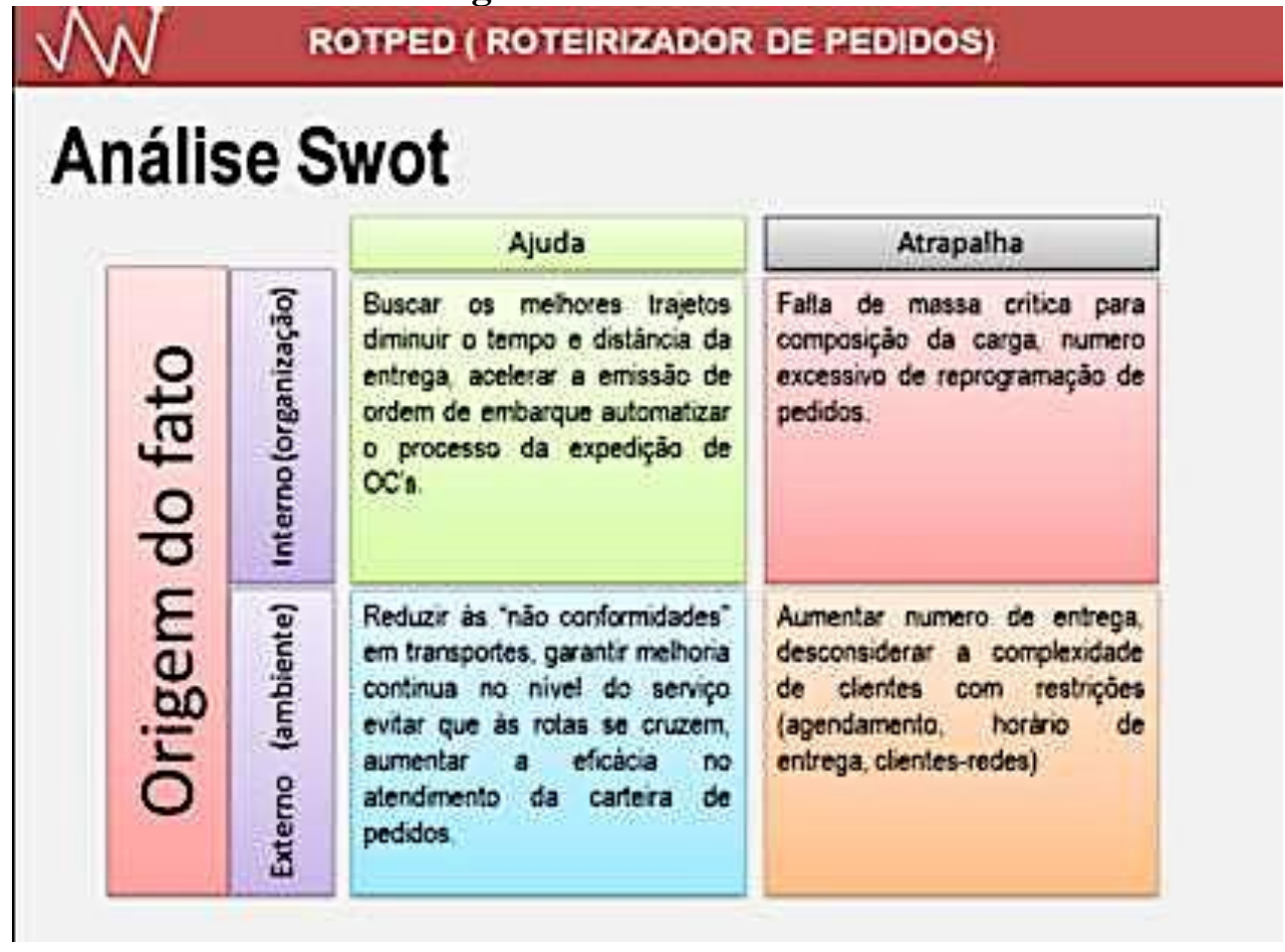

Fonte: Autores

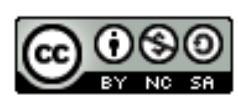


A análise SWOT traz as letras iniciais dos termos da língua inglesa $\mathrm{S}$ (Strengths), W (Weakness), O (Opportunities), T (Threats); que significam, em língua portuguesa, respectivamente, Forças, Fraquezas, Oportunidades e Ameaças.

Esse recurso é muito utilizado, normalmente, no trabalho do planejamento estratégico empresarial, ou ainda em projetos novos, porque é uma forma de diagnosticar o negócio e o seu contexto de maneira sintética e completa.

Assim, na figura acima, se demonstra os aspectos positivos desse projeto que são a otimização das entregas e redução de custos, e os aspectos negativos, que fundamentalmente são as reformulações e reprogramas que deverão ser realizados.

Figura 4. Algoritmo

\section{ROTPED (ROTEIRIZADOR DE PEDIDOS)}

\section{Algoritmo}

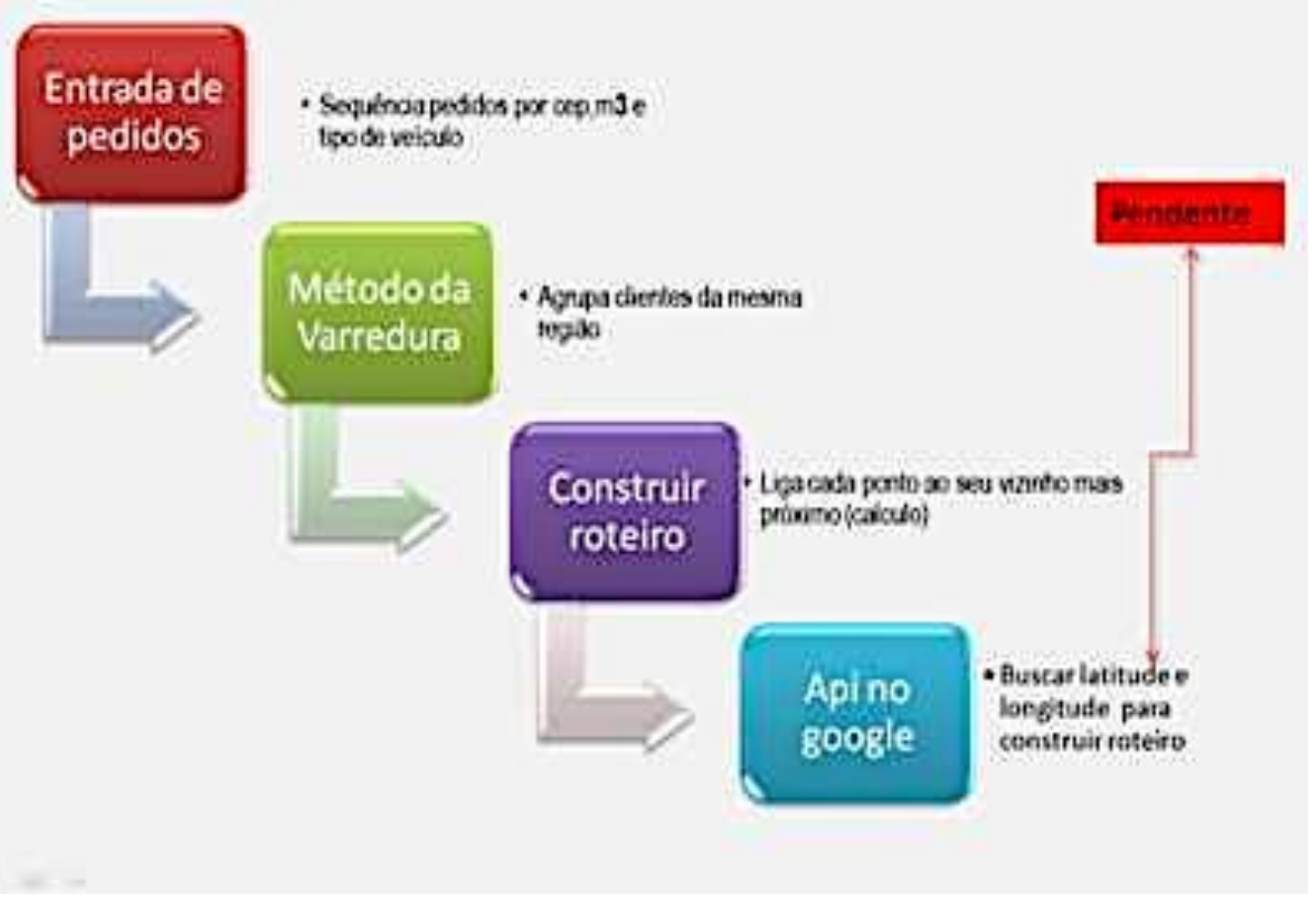

Fonte: Autores

A Figura 4 apresenta o algoritmo, destacando a forma como a tecnologia favorece esse trabalho de roteirização, facilitando e otimizando os resultados, que se refletirão nos resultados e nos custos voltados para os clientes.

$\mathrm{Na}$ imagem da sequência, Figura 5, são apresentados os inputs e outputs, que de acordo com Leão (2017), input são as entradas, sendo o primeiro item que adentra o processo de transformação; no caso do projeto, trata-se do local em que os veículos ficam, ambiente de partida e recolhida dos produtos; os outputs, que seriam a saída dos produtos, no caso do projeto, é o foco principal e final da utilização do roteirizador, que é a minimização dos custos dos produtos para os clientes.

\section{@ $\odot \Theta \odot$}


Figura 5. Inputs e Outputs

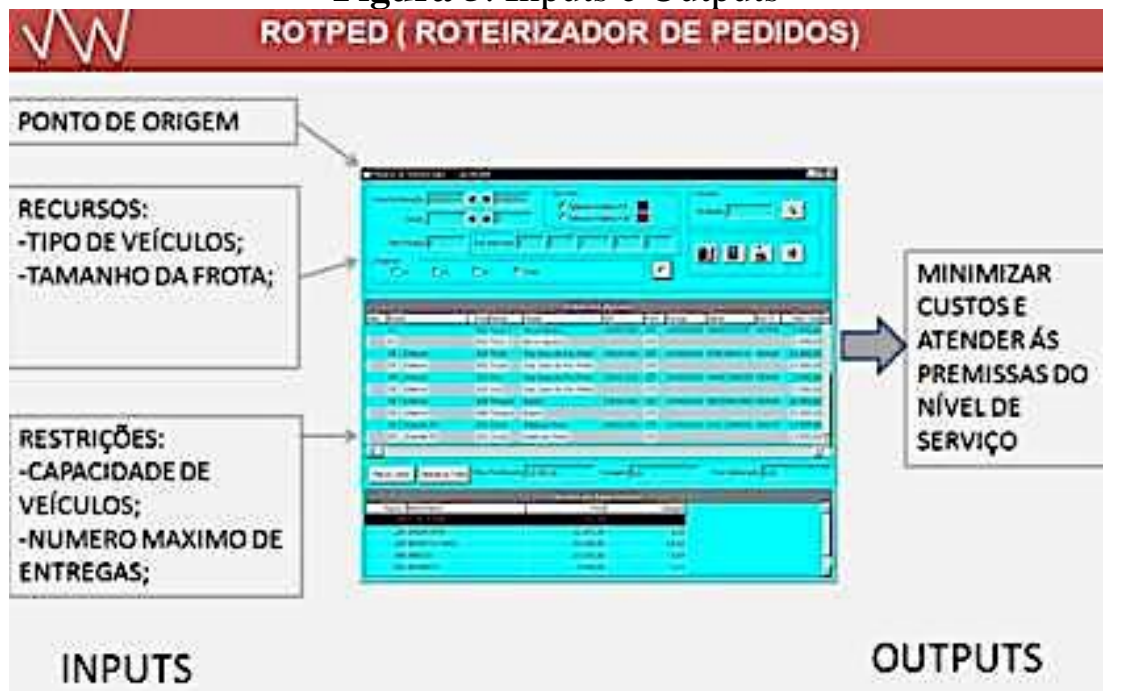

Fonte: Autores

Para que as cargas fossem otimizadas, visando a minimização das contas fretes foram realizadas as seguintes mudanças:

- Trabalho de implantação do software de roteirização;

- $\quad$ Ajustes em tabelas de preços, na margem de 15\%;

- Redução de autorizações adicionais, como auxílio de custo referente a estadias e complexidade de cargas ${ }^{1}$.

Esses auxílios precisam ser analisados individualmente, podendo ocorrer situações em que o motorista fica aguardando a descarga dos produtos por períodos maiores que dois dias.

Figura 6. Índice de aproveitamento do veículo.

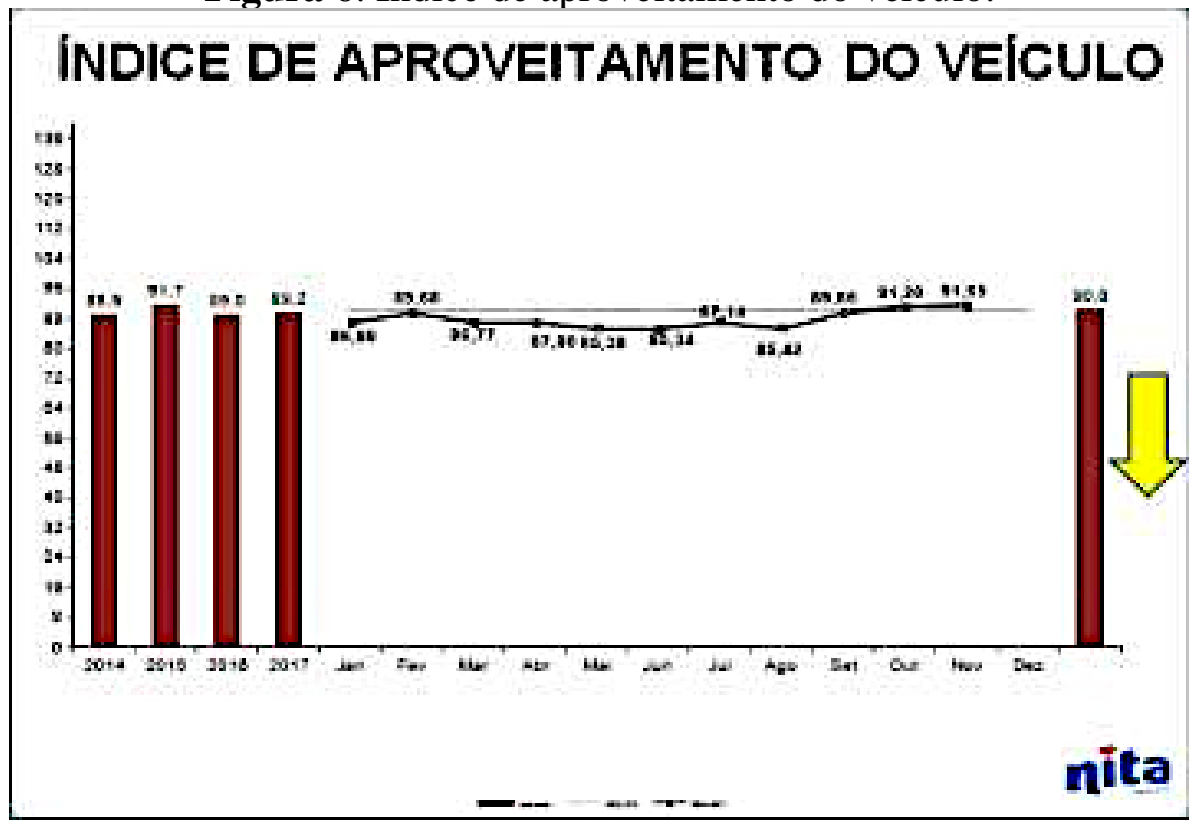

Fonte: Autores

Na Figura 6 se apresenta o gráfico do índice de aproveitamento do veículo, que é bem similar desde o ano de 2014.

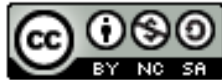


Tabela 1. Valores e reduções

\begin{tabular}{|c|c|c|c|c|c|}
\hline \multicolumn{5}{|c|}{ ENTRADA DE DADOS } & \multirow[b]{2}{*}{$\%$ AH } \\
\hline $\begin{array}{l}\text { Ano } \\
\text { Mês }\end{array}$ & Valor anual & REAL-2016 & REAL-2017 & ORÇADO & \\
\hline 2014 & 88,87 & & & & \\
\hline 2015 & 91,66 & & & & \\
\hline 2016 & 89,00 & & & & \\
\hline 2017 & 89,16 & & & & \\
\hline Jan & & 92,00 & 86,80 & 90,00 & $96,44 \%$ \\
\hline Fev & & 90,00 & 89,68 & 90,00 & $99,64 \%$ \\
\hline Mar & & 89,00 & 86,77 & 90,00 & $96,41 \%$ \\
\hline Abr & & 87,00 & 87,00 & 90,00 & $96,67 \%$ \\
\hline Mai & & 89,00 & 85,39 & 90,00 & $94,88 \%$ \\
\hline Jun & & 87,00 & 85,34 & 90,00 & $94,82 \%$ \\
\hline Jul & & 87,00 & 87,14 & 90,00 & $96,82 \%$ \\
\hline Ago & & 88,00 & 85,42 & 90,00 & $94,91 \%$ \\
\hline Set & & 89,00 & 89,65 & 90,00 & $99,61 \%$ \\
\hline Out & & 88,00 & 91,20 & 90,00 & $101,33 \%$ \\
\hline Nov & & 89,00 & 91,65 & 90,00 & $101,83 \%$ \\
\hline Dez & & 89,00 & & 90,00 & $0,00 \%$ \\
\hline \multirow[t]{2}{*}{ Benchmark } & 90,00 & & & & \\
\hline & & 89,00 & 89,16 & 90,00 & $99,07 \%$ \\
\hline
\end{tabular}

Fonte: Autores

Na Tabela 1, pode-se observar a redução nos valores no ano de 2017, em relação ao ano de 2016. Apesar de não ser uma redução muito representativa, já significa impactos nos valores finais dos produtos.

Os índices de desempenho são fundamentais, como explicam Matos Júnior et al. (2013), que destacam que é através do processo de roteirização e indicadores de desempenho logísticos que se possibilita apontar o índice de devolução de notas fiscais sobre a venda líquida, uso de capacidade total de cargas veiculares, entregas no prazo, custo da distribuição, fretes extras que são gerados por devoluções, atrasos, reentregas e vários motivos que geram custos extras em cobranças.

Por isso, é fundamental observar o processo de roteirização, para ser possível encontrar e destacar suas variações e erros, para corrigi-los devidamente.

\section{Considerações Finais}

O presente estudo contribuiu, primeiramente, para a ampliação do conhecimento teórico, com a realização da pesquisa científica, que fez compreender conceitos de logística e a importância da tecnologia no contexto do empreendedorismo atual. Atualmente, os clientes precisam ter suas necessidades sanadas e para isso, é fundamental que conquistem valores mais competitivos, oferecendo qualidade e preços mais atrativos para que os clientes possam escolher determinada empresa e seu produto ou serviço.

A implantação do projeto, com o uso do roteirizador de pedidos levou a uma otimização das cargas, podendo, de acordo com o objetivo proposto, reduzir custos de entregas, e o do produto final. Os resultados foram satisfatórios, no entanto, ainda existem fatores que impedem mais qualidade, que são: volume elevado no final do mês, os representantes incluem grandes quantidades para o fechamento e, muitas vezes, carregam cargas fora da rota, até

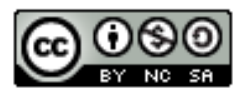


mesmo cargas ociosas, o que influencia na conta frete. Outra questão prejudicial é a urgência de cargas, que são solicitadas diretamente à diretoria da empresa .O resultado para a otimização foi positivo, exigindo melhorias no sistema vinculado ao Google Maps, para o aperfeiçoamento da roteirização. Nesse sentido, visando a minimização das contas fretes, a partir dessa pesquisa foram realizadas as seguintes mudanças na empresa que envolveu implantação do software de roteirização; ajustes em tabelas de preços, na margem de 15\%; redução de autorizações adicionais, como auxílio de custo referente a estadias e complexidade de cargas .Observou-se que com a proposta desse estudo, que a empresa ao adotar um roteirizador as entregas passam a ser mais rápidas e eficazes, atendendo às necessidades dos clientes já existentes e elevando a credibilidade da organização.

\section{Referências}

Bertaglia, P. R. (2003). Logística e Gerenciamento da Cadeia de Abastecimento - Ed Saraiva.

Ballou, R. H. (2001). Gerenciamento da Cadeia de Suprimentos. $4^{\mathrm{a}}$ ed. Porto Alegre: Bookman.

Ballou, Ronald H. (1993). Logística Empresarial: Transportes, Administração de Materiais e Distribuição Física. São Paulo: Atlas.

Bodin, L. D. (1990). Twenty years of routing and scheduling. Operations Research, 38(4), 571-579.

Branco, F. J. C.; Gigioli, O. A. (2014). Roteirização de transporte de carga - Estudo de Caso: distribuidora de tintas e seu método de entregas. Revista FAE, Curitiba, 17(2), 56-81, jul./dez.

Cunha, C. B. (2000). Aspectos Práticos da Aplicação de Modelos de Roteirização de Veículos a Problemas Reais. Transportes, 8(2), 51-74.

Leão, W. O processo de transformação: Input e Output (Entrada e saída). Disponível em: $<$ https://www.administradores.com.br/artigos/academico/o-processo-de-transformacao-input-eoutput-entrada-e-saida/78698/> Acesso em: 01 de dezembro de 2017.

Lima, C. T., \& Schebeleski, M. (2013). Logística de roteirização para uma indústria de laticínios da região de Campo Mourão: um estudo de caso. VIII Encontro de Produção Científica e Tecnológica.

Matos Junior, C. A., Nunes, R. V., Assis, C. W. C., Fonseca, R. C., Adriano, N. A., \& Santos, G. P. (2013). O papel da roteirização na redução de custos logísticos e melhoria do nível de serviço em uma empresa do segmento alimentício no Ceará. XX Congresso Brasileiro de Custos - Uberlândia, MG, Brasil.

Martin, C. (2010). Logística e o gerenciamento da cadeia de suprimentos. 2. ed. São Paulo: Cengage Learning.

Morales, S. R., Morabito, R., \& Widmer, J. A. (1997). Otimização do carregamento de produtos paletizados em caminhões. Revista Gestão e Produção, 4(2), 234-252, ago.

Novaes, A. G. (2007). Logística e Gerenciamento da Cadeia de Distribuição. 3.ed. Rio de Janeiro: Elsevier.

Pinto, R. C., Sanches, J. M., \& TófolI, E. T. A utilização da tecnologia no transporte de cargas na transportadora Veneroni de Avanhandava-SP. Disponível em: <http://www.fateclins.edu.br/site/trabalhoGraduacao/Hm21JYV8sMjZ4JpmBThqmRIMdDR9PLYjSa C YDkr.pdf> Acesso em: 01 de dezembro de 2017.

Ravagnolli, L. L. (2006). Roteirizadores para operadores logísticos: definição e apresentação. Centro Paula Souza, Jaú. $2^{\circ}$ Sem. 86 p.

Revista Logística - IMAM. A importância da TI no transporte rodoviário de cargas. Disponível em: <https://www.imam.com.br/logistica/artigos/serie-tecnologia-da-informacao/122-a-importancia-da- tino-transporte-rodoviario-de-cargas> Acesso em: 29 de novembro de 2017.

Valente, A. M. (2008). Transporte Rodoviário de Cargas. In: Qualidade e produtividade em transportes. São Paulo: Cengage Learning. 